\title{
Isolation and Characterization of an Attenuated Strain of Pseudomonas aeruginosa AC869, a 3,5-Dichlorobenzoate Degrader
}

\author{
XIN ZHOU,${ }^{1} \dagger$ S. ELIZABETH GEORGE, ${ }^{2}$ DARA W. FRANK, ${ }^{3}$ MARYJANE UTLEY, ${ }^{1}$ IAN GILMOUR, ${ }^{4}$ \\ KAREN A. KROGFELT, ${ }^{5}$ LARRY D. CLAXTON, ${ }^{2}$ DAVID C. LAUX, ${ }^{1}$ AND PAUL S. COHEN ${ }^{1 *}$ \\ Department of Biochemistry, Microbiology, and Molecular Genetics, University of Rhode Island, Kingston, Rhode

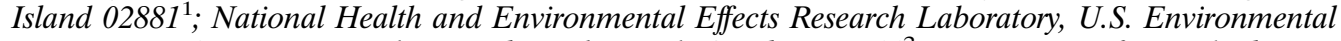 \\ Protection Agency, Research Triangle Park, North Carolina 27711 ${ }^{2}$; Department of Microbiology, \\ Medical College of Wisconsin, Milwaukee, Wisconsin 5322633 University of North Carolina, \\ Chapel Hill, North Carolina 275994; and Department of Clinical Microbiology, \\ Statens Seruminstitut, 2300 Copenhagen S, Denmark ${ }^{5}$
}

Received 4 April 1996/Accepted 31 January 1997

\begin{abstract}
Pseudomonas aeruginosa AC869, a 3,5-dichlorobenzoate degrader, is a mouse pathogen and has a reported $50 \%$ lethal dose $\left(\mathrm{LD}_{50}\right)$ of $1.05 \times 10^{7} \mathrm{CFU}$ when given intranasally to $\mathrm{C} 3 \mathrm{H} / \mathrm{HeJ}$ mice (S. E. George, M. J. Kohan, M. I. Gilmour, M. S. Taylor, H. G. Brooks, J. P. Creason, and L. D. Claxton, Appl. Environ. Microbiol. 59:35853591, 1993). AC869 was serotyped as $\mathrm{O6}$ when grown in CD-1 mouse cecal and lung mucus but could not be assigned an $O$ serotype when grown in Luria broth (LB). After growth in mouse cecal mucus, a less virulent mutant, AC869-11, was isolated from AC869 by using bacteriophage E79, which adsorbs to the $O$ side chain of lipopolysaccharide (LPS). AC869-11 produced significantly less $O$ antigen on its LPS than AC869 when grown in mouse lung and cecal mucus. The mutant also produced half the amount of exoenzyme $S$ and 16-fold less extracellular protease than AC869 and was more sensitive than its parent to a number of antibiotics when grown either in LB or in mouse lung mucus. AC869-11 had a ninefold higher LD $_{50}$ than AC869 in CD-1 mice when administered intranasally. AC869-11 was found in the lungs, small intestine, cecum, and large intestine in numbers at least 100-fold below AC869, $3 \mathrm{~h}$ after intranasal exposure of mice to a sublethal dose of the two strains. Moreover, AC869-11 induced a decreased pulmonary inflammatory response relative to AC869. In contrast to AC869, AC869-11 did not translocate to the mesenteric lymph nodes, liver, and spleen following a sublethal dose. Despite attenuation, AC869-11 grew as well as AC869 with 3,5-dichlorobenzoate as the sole carbon and energy source. However, although AC869-11 survived in 3,5-dichlorobenzoate-contaminated soil as well as AC869 for 1 week, it failed to survive as well thereafter. These results suggest the possibility that mutations that lead to pulmonary attenuation of $P$. aeruginosa in mice also lead to weakness in the environment, despite such mutants maintaining the ability to degrade toxic substances under laboratory conditions.
\end{abstract}

Members of the genus Pseudomonas are used for environmental applications as agricultural biopesticides (26), as detoxifiers of chemicals (19), and in prevention of ice nucleation on plants (20) because of their effectiveness in biocontrol and versatile substrate utilization abilities (19). For obvious reasons, the strains to be released into the environment must be strong, competitive organisms. Unfortunately, strong, competitive pseudomonads may be opportunistic human pathogens capable of causing disease, especially in immunosuppressed hosts and patients with leukemia or cystic fibrosis $(2,3,12,27)$. Human exposure to these microorganisms may occur during production or application. Because a high concentration of these microorganisms may be found in the air and water, exposure and subsequent disease may occur through inhalation and ingestion. Clearly, strong, competitive Pseudomonas strains which are still capable of performing the task for which they were designed but which are unable to colonize the lung tissue or the intestines of humans and animals should be constructed in order to minimize the risk of opportunistic infections.

Pseudomonas aeruginosa AC869 is an environmental strain that has been engineered to utilize 3,5-dichlorobenzoate as the

\footnotetext{
* Corresponding author. Phone: (401) 874-5920. Fax: (401) 8742202. E-mail: pcohen@uriacc.uri.edu.

$\dagger$ Present address: Department of Pediatrics and GI Cell Biology Laboratory, Children's Hospital and Harvard Medical School, Boston, MA 02115.
}

sole source of carbon and energy but which has been found to be pathogenic for mice when administered intranasally $(50 \%$ lethal dose $\left.\left[\mathrm{LD}_{50}\right]=1.05 \times 10^{7} \mathrm{CFU}\right)(11)$. In the present study, AC869 was used as a model to determine whether it could be attenuated without impairing its ability to degrade 3,5-dichlorobenzoate, to grow in common laboratory media, and to survive in 3,5-dichlorobenzoate-contaminated soil. Our approach was to look for new antigens associated with growth in mouse lung and cecal mucus preparations in vitro, to make mutants that no longer make these antigens, and to test such mutants for changes in virulence, ability to degrade 3,5-dichlorobenzoate, and ability to survive in 3,5-dichlorobenzoate-contaminated soil.

\section{MATERIALS AND METHODS}

Bacteria and bacteriophage. $P$. aeruginosa AC869 was engineered to utilize 3,5-dichlorobenzoate as a sole carbon and energy source (5). P. aeruginosa PAO1 has been described previously (13). The bacteriophage E79, which adsorbs to the O side chain of lipopolysaccharide (LPS) (16), and P. aeruginosa IATS 06, the host of bacteriophage E79, were provided by A. M. Kropinski from Queen's University, Kingston, Ontario, Canada.

Laboratory media and antibiotics. The strains were routinely grown at $37^{\circ} \mathrm{C}$ in Luria broth (LB) and plated on L agar, which is LB containing $12 \%$ Bacto Agar (Difco, Detroit, Mich.). M9 minimal medium was prepared as described by Miller (23). For measurement of exoenzyme S production, strains were grown in Vogel-Bonner minimal medium (29). All antibiotics were purchased from Sigma (St. Louis, Mo.).

Animals. Five- to eight-week-old CD-1 mice, used as a source of lung and cecal mucus, were obtained from Charles River Laboratories (Wilmington, Mass.) Food (Agway Prolab Rat/Mouse/Hamster 3000 Formula) and deionized water 
were provided ad libitum, and the mice were housed in polycarbonate cages containing pine shavings. For $\mathrm{LD}_{50}$ and clearance studies, 35-day-old male CD-1 mice were fed Purina Rodent Chow 5001 (Purina Mills, Inc., St. Louis, Mo.). Deionized water was provided ad libitum, and the mice were housed in polycarbonate cages (five mice per cage) containing pine shavings. The animals were quarantined for 10 days prior to treatment.

Mucus isolation. Thirty mice were sacrificed by $\mathrm{CO}_{2}$ asphyxiation and were dissected aseptically. A small incision was made in the trachea, and a 1-in. (2.54 $\mathrm{cm})$ 22-gauge feeding needle was introduced into the airway. Heavy thread was tied around the trachea at the tip of the needle to prevent leakage. A $10-\mathrm{ml}$ syringe containing $5 \mathrm{ml}$ of sterile HEPES-Hanks buffer, $\mathrm{pH} 7.4(\mathrm{HH})$, was connected to the needle, and the lungs were inflated and deflated several times with $\mathrm{HH}$. Backflushed $\mathrm{HH}$ was collected and called crude lung mucus. Ceca were then removed and placed in sterile $\mathrm{HH}$. Ceca were nicked at each end, and the luminal contents were removed by gentle scraping with a rubber spatula. The ceca were then transferred to a second petri dish and gently agitated in sterile $\mathrm{HH}$ to remove any debris. Scraping of the walls of the ceca was conducted in a third petri dish containing $5 \mathrm{ml}$ of sterile $\mathrm{HH}$. This scraping removed the mucus layer, which remained soluble in $\mathrm{HH}$ (7). The crude lung and cecal mucus preparations were then centrifuged at $12,000 \times g$ for $10 \mathrm{~min}$ followed by a $27,000 \times g$ centrifugation of the supernatant for $15 \mathrm{~min}$. The pellets contained cellular, tissue, and fecal contaminants. The supernatants from cecal mucus and lung mucus preparations will be referred to as CM and LM, respectively. All centrifugations were carried out at $4^{\circ} \mathrm{C}$, and mucus preparations were placed on ice during processing. $\mathrm{CM}$ and $\mathrm{LM}(1 \mathrm{mg}$ of protein per $\mathrm{ml})$ were then sterilized in a sterile plastic petri dish for $15 \mathrm{~min}$ with UV light $(254 \mathrm{~nm})$. The UV box contained three 15-W UV bulbs both on the top and at the bottom of the plates. The distance of the UV source from the top and from the bottom of the plates was 12 and $5 \mathrm{~cm}$, respectively. The UV bulb in the middle of each row of bulbs was $8 \mathrm{~cm}$ from its neighboring bulb on each side.

Growth in mucus. For immunoblotting experiments, $P$. aeruginosa strains, grown by shaking in $\mathrm{LB}$ at $37^{\circ} \mathrm{C}$ overnight, were washed twice in sterile $\mathrm{HH}$ and resuspended in sterile $\mathrm{HH}$ at the same concentration. They were then diluted in sterile $\mathrm{HH}$ and inoculated at about $10^{4}$ CFU per $\mathrm{ml}$ into LB, CM (1 mg of protein per $\mathrm{ml}$ ), and $\mathrm{LM}$ ( $1 \mathrm{mg}$ of protein per $\mathrm{ml}$ ). The cultures were incubated standing at $37^{\circ} \mathrm{C}$ for $24 \mathrm{~h}$, and cells were harvested by centrifugation at $12,000 \times g$ for 10 min, washed twice in $\mathrm{HH}$, and used either for whole cell immunoblots or for LPS extractions as described below. For determination of growth rates, strains grown by shaking in $\mathrm{LB}$ at $37^{\circ} \mathrm{C}$ overnight were washed twice in sterile $\mathrm{HH}$ and diluted in sterile $\mathrm{HH}$, and each was inoculated at about $10^{5} \mathrm{CFU}$ per ml into LB, CM (1 $\mathrm{mg}$ of protein per $\mathrm{ml})$, and $\mathrm{LM}$ (1 $\mathrm{mg}$ of protein per $\mathrm{ml})$. The cultures, incubated at $37^{\circ} \mathrm{C}$ standing for $0,3,6,9$, and $24 \mathrm{~h}$, were diluted and plated on $\mathrm{L}$ agar plates. Plates were incubated from 20 to $24 \mathrm{~h}$ at $37^{\circ} \mathrm{C}$ prior to counting.

Protein assay. The protein concentration in mucus or in $P$. aeruginosa preparations was determined by the Bio-Rad protein assay (Bio-Rad, Rockville Center, N.Y.), which is based on the method of Bradford (4). Assays were performed according to package instructions with bovine serum albumin as the standard.

Bacteriophage E79. High-titered bacteriophage E79 stocks were obtained as follows. A series of 10 -fold dilutions of E79 were mixed with $3 \mathrm{ml}$ of Luria soft agar ( $7 \mathrm{~g}$ of agar per liter) at $48^{\circ} \mathrm{C}, 3$ drops of $P$. aeruginosa IATS 06 overnight culture was added to each soft agar tube and mixed, and the mixtures were poured onto L agar plates. E79 was collected by washing plates containing confluent plaques with $5 \mathrm{ml}$ of LB after incubation at $30^{\circ} \mathrm{C}$ overnight. The collected mixture was then centrifuged at $12,000 \times \mathrm{g}$ for $10 \mathrm{~min}$, and the titer of the supernatant containing phage E79 was determined.

Isolation of bacteriophage E79-resistant mutants of $P$. aeruginosa AC869. $P$. aeruginosa AC869 was grown in $\mathrm{CM}$ at $37^{\circ} \mathrm{C}$ without shaking. One-hundredmicroliter aliquots of the culture in 3-ml aliquots of Luria soft agar were mixed with $100-\mu \mathrm{l}$ aliquots of phage E79 $\left(10^{10}\right.$ PFU per $\left.\mathrm{ml}\right)$, which had been shown previously to interact with the LPS of smooth PAO1 strains $(14,16)$, and the mixtures were then poured on L agar plates. After $24 \mathrm{~h}$ of incubation at $37^{\circ} \mathrm{C}$, several colonies were selected and purified by streaking. All selected E79-resistant colonies were identified as $P$. aeruginosa by streaking on $P$. aeruginosa isolation agar (Difco) and use of API 20E strips (Analytab Products, Plainview, N.Y.). E79-resistant colonies were not observed when $100-\mu l$ aliquots of phage E79 in Luria soft agar were poured on L agar plates.

Intranasal exposure and $\mathbf{L D}_{\mathbf{5 0}}$ s. Strains were grown in $\mathrm{LB}$ by shaking at $37^{\circ} \mathrm{C}$ overnight, the animals were anesthetized with methoxyfluorane in a desiccator jar, and $50 \mu \mathrm{l}$ of phosphate-buffered saline (PBS) or $50 \mu \mathrm{l}$ of a cell suspension was injected into the nasal cavity of each mouse with a $2.54-\mathrm{cm}, 22$-gauge feeding needle. Mice were observed for 14 days following infection. All deaths occurred by day 4 , after which mice that survived became increasingly healthy as determined by general appearance and increase in weight. $\mathrm{LD}_{50} \mathrm{~s}$ were determined by treating five animals per dose of bacteria. $\mathrm{LD}_{50} \mathrm{~s}$ were calculated following linear regression analysis of a semilogarithmic plot of the mortality data.

Enumeration of administered bacterial strains obtained from lungs, small intestine, cecum, large intestine, spleen, liver, and mesenteric lymph nodes. Strains were grown in yeast extract-tryptone broth (11) to prepare the suspensions used for administration to mice. Enumeration of these suspensions was done on yeast extract-tryptone agar $(1.5 \%)$ following dilution in Dulbecco PBS (GIBCO Laboratories, Grand Island, N.Y.). At $3 \mathrm{~h}$ and 1, 2, 5, 7, 10, and 14 days following administration of bacteria intranasally, as described above, mice were sacrificed by $\mathrm{CO}_{2}$ asphyxiation and were dissected aseptically. The lungs, small intestine, cecum, large intestine, spleen, liver, and mesenteric lymph nodes were removed from each mouse and homogenized in $5 \mathrm{ml}$ of PBS. The homogenates were diluted in PBS and plated for enumeration of P. aeruginosa on Pseudomonas isolation agar (Difco) supplemented with $50 \mu \mathrm{g}$ of kanamycin per ml. This level of kanamycin allowed a 100\% plating efficiency of AC869 and AC869-11 relative to unsupplemented Pseudomonas isolation agar. Plates were counted following $48 \mathrm{~h}$ of incubation at $37^{\circ} \mathrm{C}$. Representative colonies were subcultured, and antibiotic sensitivity was determined by using antibiotic disks (BBL Microbiology Systems, Cockeysville, Md.) to eliminate contaminants in the enumeration of the strain administered. For each experiment, three animals per treatment per time point were used. Duplicate experiments were performed, and the data presented are from both experiments.

Pulmonary inflammatory response. Sets of four CD-1 mice were sacrificed by injecting sodium pentobarbital (150 mg per $\mathrm{kg}$ of body weight) intraperitoneally at $1,2,5,7$, and 14 days following treatment, and cells were collected from the lungs by bronchoalveolar lavage. Each trachea was cannulated, and the lungs were flushed three times with warm saline $(35 \mathrm{ml}$ per $\mathrm{kg})$. Cytospin preparations were stained with Diff-Quick (Baxter Diagnostics, Inc., McGaw Park, Ill.), and alveolar macrophages, polymorphonuclear leukocytes, and lymphocytes were determined by examining 200 representative cells.

Preparation of antisera. Antisera were prepared against $P$. aeruginosa AC869 grown in LB, CM, and LM. Briefly, $25 \mathrm{ml}$ of $P$. aeruginosa AC869 grown in LB $\mathrm{CM}$, and LM was washed twice in $\mathrm{HH}$ buffer, resuspended in $0.5 \mathrm{ml}$ of $0.85 \%$ saline containing $0.3 \%$ formalin, mixed with $0.7 \mathrm{ml}$ of incomplete Freund's adjuvant, and injected into rabbits intramuscularly and subcutaneously ( 0.1 to 0.2 $\mathrm{ml}$ per site). Rabbits were then boosted at 2 months and subsequently bled 2 weeks after the last injection. Sera raised against LB-grown, CM-grown, and LM-grown AC869 will be referred to as LB-anti-AC869, CM-anti-AC869, and LM-anti-AC869 sera, respectively.

KDO assay. 2-Keto-3-deoxyoctonate (KDO) was determined by the method of Karkhanis et al. (15). The ammonium salt of KDO (Sigma Chemical Co.) was used as the standard.

Isolation of LPS. Cells were resuspended in $1 \mathrm{ml}$ of PBS and vortexed, and tubes were incubated at $60^{\circ} \mathrm{C}$ for $30 \mathrm{~min}$. The suspension was centrifuged at $11,750 \times g$ for $30 \mathrm{~min}$. One hundred microliters of the supernatant was added to $100 \mu \mathrm{l}$ of sample buffer $(62.5 \mu \mathrm{M}$ Tris- $\mathrm{HCl}$ [pH 6.8], $10 \%$ glycerol, $2 \%$ [wt/vol] sodium dodecyl sulfate [SDS], $0.05 \%$ [wt/vol] 2-B-mercaptoethanol, $0.00125 \%$ [wt/vol] bromophenol blue), and the mixture was boiled for $10 \mathrm{~min}$. The rest of the supernatant was stored at $4^{\circ} \mathrm{C}$. Fifty microliters of the boiled sample was added to $10 \mu \mathrm{l}$ of a protease $\mathrm{K}$ solution $(2.5 \mathrm{mg}$ of protease $\mathrm{K}$ per $\mathrm{ml}$ of sample buffer) and was then incubated at $60^{\circ} \mathrm{C}$ for $60 \mathrm{~min}$, the mixture was centrifuged at $16,000 \times g$ for $30 \mathrm{~min}$, and an appropriate volume of supernatant $(0.03 \mu \mathrm{g}$ of $\mathrm{KDO}$ ) was applied to an SDS-polyacrylamide gel electrophoresis (PAGE) gel for analysis. This method is used routinely for extracting LPS from small numbers of CFU at the Statens Seruminstitut, Copenhagen, Denmark (26a).

SDS-PAGE. One-dimensional SDS-PAGE was performed at $200 \mathrm{~V}$ for $30 \mathrm{~min}$ in a Mini-Protean II electrophoresis cell (Bio-Rad Laboratories, Richmond, Calif.) with $4 \%$ stacking gels and $12 \%$ separating gels.

Silver staining of LPS. A modification of a sensitive silver staining technique for detecting LPSs in polyacrylamide gels was used (8). Briefly, gels were fixed in $40 \%$ ethanol-5\% acetic acid in a clean glass dish overnight, and fixing solution was then replaced with $0.7 \%$ periodic acid in $40 \%$ ethanol-5\% acetic acid for 30 min. Silver staining was then performed according to package instructions with the Bio-Rad silver stain kit (Bio-Rad Laboratories).

Immunoblotting. Immunoblots of SDS-PAGE gels were performed as described in the package instructions from Zymed Laboratories, Inc. (South San Francisco, Calif.). Briefly, gels were blotted to $0.45-\mu \mathrm{m}$-pore-size nitrocellulose membranes (Bio-Rad Laboratories) at $60 \mathrm{~V}$ for $20 \mathrm{~min}$ (Mini-Transblot electrophoretic transfer cell apparatus; Bio-Rad Laboratories), incubated in Tris-buffered saline (TBS) $(0.15 \mathrm{M} \mathrm{NaCl}, 0.05 \mathrm{M}$ Tris- $\mathrm{HCl}, \mathrm{pH} 7.2)$ with $3 \%$ skim milk for $30 \mathrm{~min}$ at room temperature, and then reacted with a 1:1,000 dilution of a rabbit antiserum for $1 \mathrm{~h}$. The blots were then incubated in a 1:200 dilution of goat anti-rabbit immunoglobulin G-gold conjugate (Zymed Laboratories, Inc.) for $2 \mathrm{~h}$ at room temperature. Reactivity was detected by enhancement with a SilvEnhance Blot kit (Zymed Laboratories, Inc.). Antisera were diluted in TBS containing $0.05 \%$ Tween $20,0.4 \%$ gelatin, and $0.1 \%$ bovine serum albumin. Membranes were washed in TBS containing $0.05 \%$ Tween 20 .

Antibiotic sensitivity. A series of twofold dilutions of each antibiotic were made in LB or LM (1 mg of protein per $\mathrm{ml}$ ) to obtain the appropriate concentrations. Strains to be tested were grown overnight by shaking in $\mathrm{LB}$ at $37^{\circ} \mathrm{C}$. Cells were collected after centrifugation and were then washed twice with sterile $\mathrm{HH}$ buffer. Approximately $10^{5} \mathrm{CFU}$ per ml was inoculated into each tube containing an antibiotic and to one tube not containing an antibiotic, which served as the control. After $24 \mathrm{~h}$ of standing incubation at $37^{\circ} \mathrm{C}$, cells were diluted and plated on L agar plates. Plates were incubated from 20 to $24 \mathrm{~h}$ at $37^{\circ} \mathrm{C}$ prior to counting. We define the MIC as the lowest concentration of an antibiotic that reduced growth by at least 1 order of magnitude relative to the untreated culture and the $\mathrm{MBC}$ as the lowest concentration of an antibiotic that resulted in CFU per milliliter at least 1 order of magnitude lower than that at inoculation. All 
experiments were repeated at least once. Results of typical experiments are shown.

Extracellular protease activity. Strains were grown in $0.5 \mathrm{ml}$ of $\mathrm{LB}$ at $37^{\circ} \mathrm{C}$ standing for $24 \mathrm{~h}$ to about $10^{9} \mathrm{CFU}$ per $\mathrm{ml}$ and centrifuged at $8,000 \times g$ for 10 min. Cell-free LB supernatants were collected after seven successive centrifugations at $8,000 \times g$ for $10 \mathrm{~min}$. Ten microliters of supernatants and twofold serial dilutions of supernatants were pipetted onto casein agar plates (nutrient agar [Difco] plus $1 \%$ skim milk powder). Casein agar plates were inspected for protease activity (clear zones) after $16 \mathrm{~h}$ of incubation at $37^{\circ} \mathrm{C}$. All experiments were repeated once, and three replicates were performed for each experiment.

Culture conditions for exoenzyme $\mathbf{S}$ production. Bacterial cultures were grown on Vogel-Bonner minimal medium (29) at $37^{\circ} \mathrm{C}$ for 18 to $24 \mathrm{~h}$. For maximal exoenzyme S production, deferrated Trypticase soy broth (10-ml culture volume) with $100 \mathrm{mM}$ monosodium glutamate, $1 \%$ glycerol, and $10 \mathrm{mM}$ nitrilotriacetic acid (NTA) was inoculated with colonies from minimal medium plates and shaken at $32^{\circ} \mathrm{C}$ for 12 to $14 \mathrm{~h}$. As exoenzyme S production is severely reduced when $P$. aeruginosa is grown in the absence of NTA (28), enzyme activity was also assessed under these growth conditions as a negative control.

Exoenzyme S ADP-ribosyltransferase assay. Exoenzyme S activity was quantitated by ADP ribosylation of the target protein soybean trypsin inhibitor (SBTI) as described previously (10). Briefly, reaction mixtures contained 200 mM sodium acetate ( $\mathrm{pH} 6.0), 30 \mu \mathrm{M}$ soybean trypsin inhibitor, $30 \mu \mathrm{M}$ adenylate${ }^{32} \mathrm{P}-\mathrm{NAD}$ (specific activity, $0.1 \mathrm{Ci} / \mathrm{mmol}$; New England Nuclear), $2 \mu \mathrm{g}$ of wheat germ extract (source for factor-activating exoenzyme $\mathrm{S}$ ) or (factor-activating exoenzyme S) (6), and titrations of spent culture medium as a source for the enzyme. The total reaction volume was $40 \mu \mathrm{l}$. Enzyme reaction mixtures were incubated at $25^{\circ} \mathrm{C}$ for $30 \mathrm{~min}$, and reactions were stopped by the addition of SDS-PAGE sample buffer containing 2-mercaptoethanol. A portion of the reaction was analyzed by SDS- $13.5 \%$ PAGE. To visualize the SBTI band, the gel was stained with Coomassie blue, destained, and dried. The band corresponding to SBTI was cut from the dried gel, and the incorporation of $\left[{ }^{32} \mathrm{P}\right] \mathrm{ADP}$-ribose from NAD was measured by scintillation counting. Data are expressed as units of activity. One unit of activity is defined as 1 pmol of $\left[{ }^{32} \mathrm{P}\right]$ ADP-ribose incorporated into SBTI per $\mu \mathrm{l}$ of spent culture medium per min per absorbance at 540 $\mathrm{nm}\left(A_{540}\right)$ of the culture at the time of harvest.

Antigen preparation for immunoblot analysis of exoenzyme S. Cultures were grown for maximal exoenzyme $\mathrm{S}$ production and harvested in stationary phase. Whole-culture samples $(300 \mu \mathrm{l})$, which included both cells and spent medium, were sonicated for $45 \mathrm{~s}, 50 \%$ duty cycle, at a power setting of three, with a Branson Model 200 microtip sonicator (Danbury, Conn.). To obtain a cell lysate, free of spent medium, $300 \mu \mathrm{l}$ of culture was subjected to a brief centrifugation $\left(12,000 \times g, 2 \mathrm{~min}, 4^{\circ} \mathrm{C}\right)$. The supernatant material was discarded, and the cell pellet was washed twice in ice-cold wash buffer containing $50 \mathrm{mM}$ Tris $\mathrm{HCl}(\mathrm{pH}$ 8.0), $20 \mathrm{mM}$ EDTA, $10 \mathrm{mM}$ benzamidine, and $1 \mu \mathrm{g}$ of leupeptin per $\mathrm{ml}$. The final cell pellet was suspended in $300 \mu \mathrm{l}$ of the wash buffer and sonicated. Extracellular material or spent culture medium was obtained by removing the cells by centrifugation $\left(12,000 \times g, 5 \mathrm{~min}, 4^{\circ} \mathrm{C}\right)$ and harvesting the supernatant. A portion of spent medium was concentrated approximately 10 -fold by the addition of a saturated solution of ammonium sulfate to a final concentration of $55 \%$. After a 2-h incubation on ice, precipitated extracellular proteins were collected by centrifugation $\left(12,000 \times g, 15 \mathrm{~min}, 4^{\circ} \mathrm{C}\right)$. Samples for SDS-PAGE $(11 \% \mathrm{gel})$ and immunoblot analysis were normalized to the $A_{540}$ reading at the time of harvest, suspended in SDS sample buffer, and boiled for $5 \mathrm{~min}$ in the presence of 2 -mercaptoethanol. Lanes were loaded with $5 \mu \mathrm{l}$ of each extract, which represented a $1 \times$ concentration of whole culture, cellular lysate, or supernatant, or $10 \times$ concentrated supernatant. Immunoblot analysis was performed with a rabbit-specific antiserum raised against both the $49-\mathrm{kDa}$ and the $53-\mathrm{kDa}$ forms of exoenzyme $\mathrm{S}(9)$ as the probe and ${ }^{125}$ I-labeled protein $\mathrm{A}$ as the secondary reagent, as described previously (10).

O serotyping. O serotyping was performed at the Statens Seruminstitut as described by Liu et al. (21).

Degradation of 3,5-dichlorobenzoate. P. aeruginosa AC869 and AC869-11 were grown on M9 minimal medium agar plates containing $1 \mathrm{mg}$ of 3,5-dichlorobenzoate per $\mathrm{ml}$ (added to 1 liter as $1 \mathrm{~g}$ dissolved in $1 \mathrm{ml}$ of dimethyl sulfoxide [Aldrich Chemical Co., Milwaukee, Wis.]). M9 agar medium with dimethyl sulfoxide $(1 \mathrm{ml} /$ liter $)$ was used as a negative control. Purified agar (12 g/liter; Sigma) was used in making all M9 plates. Plates were inoculated with $10^{7}$ $\mathrm{CFU} /$ plate and incubated at $30^{\circ} \mathrm{C}$. At $24-\mathrm{h}$ intervals, over a 72 -h period, bacteria were removed from a set of plates with a sterile spreading rod after adding $5 \mathrm{ml}$ of sterile saline to each plate. Samples were read for $A_{600}$ and plated on $\mathrm{L}$ agar plates for viable counts. L agar plates were incubated at $37^{\circ} \mathrm{C}$ for $24 \mathrm{~h}$ prior to counting.

Survival in 3,5-dichlorobenzoate-contaminated soil. Cultures of AC869 and AC869-11 were grown at $37^{\circ} \mathrm{C}$ overnight in $\mathrm{LB}$ with vigorous aeration, washed twice separately in sterile water, and resuspended separately at a concentration of $4.0 \times 10^{7}$ per $\mathrm{ml}$ in $80 \mathrm{ml}$ of sterile water containing $1 \mathrm{mg}$ of 3,5-dichlorobenzoate per $\mathrm{ml}$. Three $25-\mathrm{ml}$ aliquots of AC 869 were added to three separate 100 -g samples of sterile surface soil-(collected from surface soil used for growing turf at the University of Rhode Island) in 250-ml Erlenmeyer flasks. Three other 100 -g samples of sterile soil were inoculated with three $25-\mathrm{ml}$ aliquots of AC86911. Soil cultures were incubated at $24^{\circ} \mathrm{C}$ for various times, and 5 -g samples were taken into $5 \mathrm{ml}$ of $0.9 \%$ (wt/vol) $\mathrm{NaCl}$, vortexed, and plated on $\mathrm{L}$ agar plates.

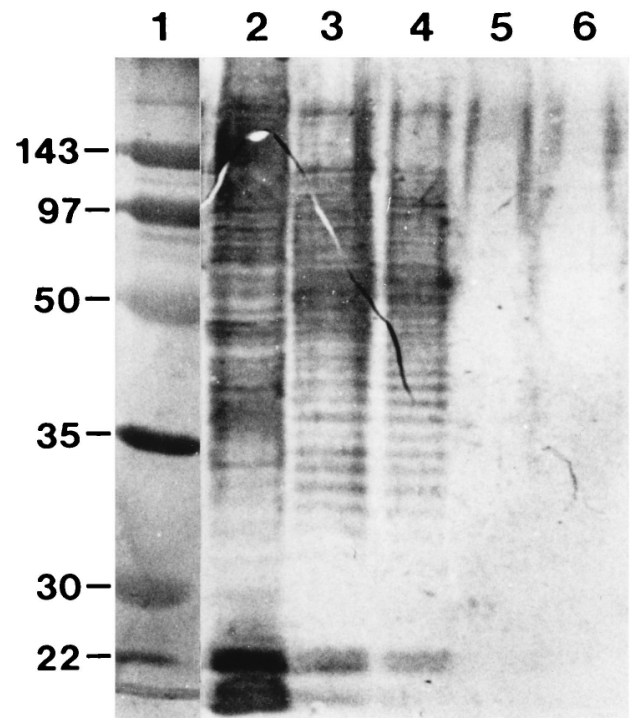

FIG. 1. Immunoblots of AC869 whole cells probed with CM-anti-AC869 sera. AC869 was grown in LB, CM, and LM. Whole cells (15 $\mu \mathrm{g}$ of protein) or mucus (15 $\mu \mathrm{g}$ of protein), subjected to SDS-PAGE, was probed on blots with CM-anti-AC869 serum. Lane 1, protein standards; lane 2, AC869 grown in LB; lane 3, AC869 grown in CM; lane 4, AC869 grown in LM; lane 5, CM; lane 6, LM. Numbers on the left denote protein standards in kilodaltons.

Plates were incubated at $37^{\circ} \mathrm{C}$ for 18 to $24 \mathrm{~h}$ prior to counting. This experiment was repeated once with essentially the same result as presented here. Soil samples were sterilized once each day for 4 consecutive days in 100-g aliquots in 250-ml Erlenmeyer flasks prior to inoculation.

\section{RESULTS}

Immunoblotting of $P$. aeruginosa AC869 whole cells probed with anti-AC869 sera. When equal amounts of protein from LB-grown, CM-grown, and LM-grown cells were examined by immunoblotting, a stepladder configuration was observed between 35 and $70 \mathrm{kDa}$ in CM-grown cells (Fig. 1, lane 3 ) and LM-grown cells (Fig. 1, lane 4) but not in LB-grown cells (Fig. 1, lane 2) probed with CM-anti-AC869 serum or LM-antiAC869 serum (not shown). The AC869 anticecal serum was consistently stronger and therefore was used throughout this study. The stepladder configurations, reminiscent of LPS (22), were not observed when the same preparations were probed with LB-anti-AC869 serum (not shown). Since the CM-antiAC869 serum did not cross-react with CM (Fig. 1, lane 5) and LM (Fig. 1, lane 6), the stepladder configuration was clearly due to $P$. aeruginosa AC869.

Silver staining and $O$ serotyping of $P$. aeruginosa AC869 LPS. LPS purified from AC869 grown in LB, CM, and LM was subjected to SDS-PAGE and silver stained. Presumptive O side chain in high-molecular-weight clusters of bands was associated with AC869 LPS isolated from CM- and LM-grown cells (Fig. 2, lanes 3 and 4), but high-molecular-weight clusters were not observed in the same amount of LPS isolated from LB-grown cells (Fig. 2, lane 2). This suggested that, when grown in CM or LM, AC869 synthesized far more O side chain than when AC869 was grown in LB. In support of this view, AC869 grown in both CM and LM was serotyped as O6 whereas the same strain grown in LB could not be assigned an O serotype when tested with standard O serotyping sera.

Immunoblots of LPS isolated from $P$. aeruginosa AC869 probed with CM-anti-AC869 serum. LPS isolated from AC869 grown in LB, CM, and LM was subjected to SDS-PAGE and 


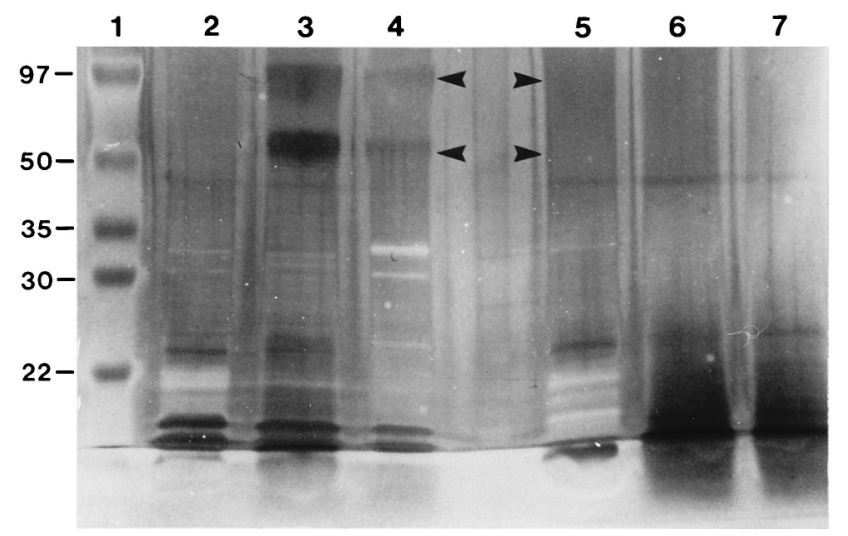

FIG. 2. Silver stain of AC869 and AC869-11 LPS preparations. LPS was extracted from strains AC869 and AC869-11 grown in LB, CM, and LM. LPS $(0.03 \mu \mathrm{g}$ of $\mathrm{KDO})$ from each sample was subjected to SDS-PAGE and silver stained. Lane 1, protein standards; lane 2, AC869 LPS from LB-grown cells; lane 3, AC869 LPS from CM-grown cells; lane 4, AC869 LPS from LM-grown cells; lane 5, AC869-11 LPS from LB-grown cells; lane 6, AC869-11 LPS from CMgrown cells; lane 7, AC869-11 LPS from LM-grown cells. Arrowheads indicate positions of high-molecular-weight LPS molecules. Numbers at left are molecular masses in kilodaltons.

probed with CM-anti-AC869 serum on blots (Fig. 3). LPS isolated from AC869 grown in CM and LM (Fig. 3, lanes 3 and 4) contained a definite stepladder configuration which was not detectable in LPS isolated from AC869 grown in LB (Fig. 3, lane 2). High-molecular-weight clusters of bands were observed in all three LPS preparations, but the intensities of these clusters were highest in LPS preparations isolated from LM- and CM-grown cells (Fig. 3).

It was possible that something in $\mathrm{CM}$ and $\mathrm{LM}$ induced $\mathrm{O}$ side chain synthesis or that $\mathrm{L}$ broth inhibited $\mathrm{O}$ side chain synthesis. Therefore, lung mucus was collected from the lungs of CD-1 mice in L broth and AC869 was grown in L broth and $\mathrm{L}$ broth supplemented with lung mucus (1 mg of protein per $\mathrm{ml})$. LPS was extracted from both cultures, and equal amounts were tested for the stepladder configuration on blots probed with CM-anti-AC869 serum. LPS isolated from the mucussupplemented L broth culture contained a definite stepladder configuration and intense high-molecular-weight clusters of bands whereas the LPS isolated from the L broth culture did

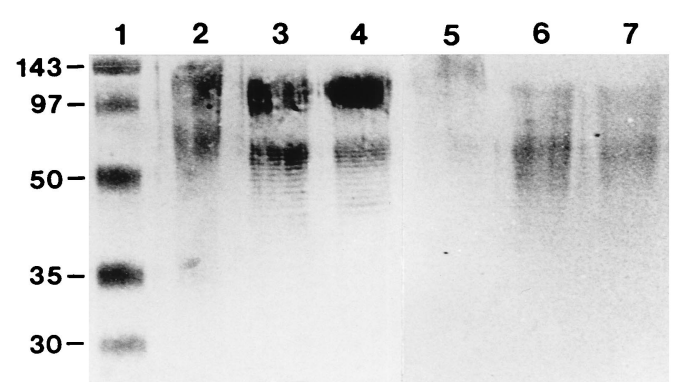

FIG. 3. Immunoblot of LPS isolated from AC869 and AC869-11 probed with CM-anti-AC869 serum. LPS was extracted from strains AC869 and AC869-11 grown in LB, CM, and LM. LPS (0.03 $\mu \mathrm{g}$ of KDO) from each sample was subjected to SDS-PAGE, and a blot was probed with CM-anti-AC869 serum. Lane 1, protein standards; lane 2, AC869 LPS from LB-grown cells; lane 3, AC869 LPS from CM-grown cells; lane 4, AC869 LPS from LM-grown cells; lane 5, AC869-11 LPS from LB-grown cells; lane 6, AC869-11 LPS from CM-grown cells; lane 7, AC869-11 LPS from LM-grown cells. Numbers at left are molecular masses in kilodaltons.

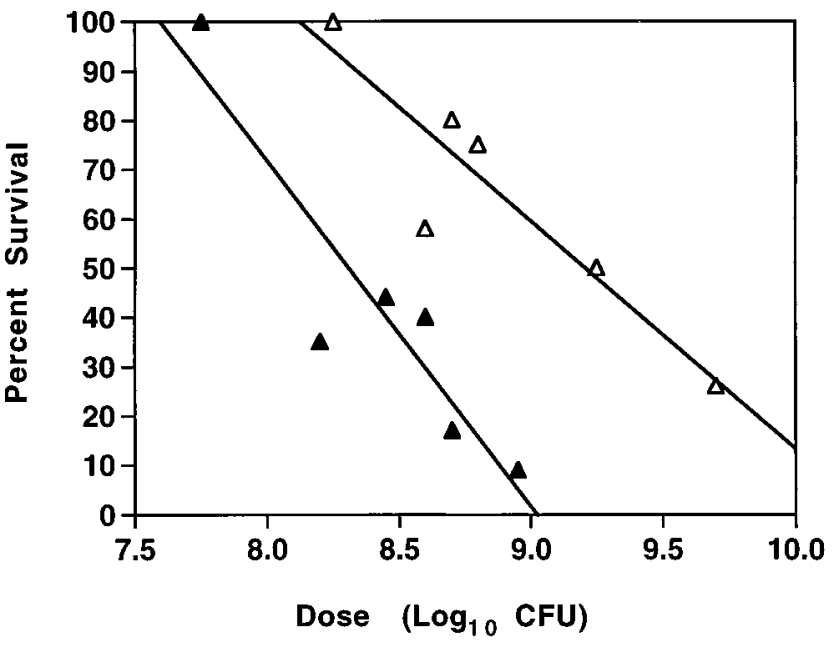

FIG. 4. Survival of mice infected with AC869 and AC869-11. AC869 and AC869-11 were administered intranasally at the indicated doses as described in Materials and Methods. Symbols: $\boldsymbol{\Delta}$, AC869; $\triangle$, AC869-11.

not (not shown), suggesting that lung mucus contains an inducer of $\mathrm{O}$ side chain synthesis.

Isolation and testing of LPS mutants in mice. Because AC869 synthesized more O6 when grown in CM and LM than when grown in LB, it became of great interest to isolate LPS mutants of AC869 and determine the effect on pathogenesis. Using phage E79, which adsorbs to $\mathrm{O}$ side chain (16), we were able to isolate E79-resistant AC869 mutants. Six E79-resistant mutants were selected for testing in mice. Each mutant $(2 \times$ $\left.10^{8} \mathrm{CFU}\right)$ was administered to three CD-1 mice intranasally. Strain AC869 and PBS were used as controls. Five of the six mutants appeared to be as virulent as their parent, killing all three mice overnight, but the sixth, designated AC869-11, killed only one mouse and that mouse died at least $8 \mathrm{~h}$ later than the mice infected with the other five mutants. The other two mice infected with AC869-11 appeared ruffled and lethargic for 2 days but then regained a normal, healthy appearance and survived indefinitely. All three mice treated with PBS survived and appeared healthy throughout the duration of the experiment. A more detailed study of AC869-11 pathogenesis was then undertaken.

$\mathbf{L D}_{\mathbf{5 0}}$ s. The $\mathrm{LD}_{50}$ s of $\mathrm{AC} 869$ and AC869-11 were determined. Five animals were used at each dose for each strain in each experiment, and the data derived from two separate experiments were combined and are presented. The $\mathrm{LD}_{50} \mathrm{~s}$ of strains AC869 and AC869-11 were found to be $1.91 \times 10^{8}$ and $1.55 \times 10^{9} \mathrm{CFU}$, respectively (Fig. 4); i.e., the $\mathrm{LD}_{50}$ of AC869-11 was about nine times higher than that of AC869. The correlation coefficients of the $\mathrm{LD}_{50} \mathrm{~s}$ of strains AC869 and AC869-11 were both 0.82 . The $\mathrm{LD}_{50}$ of AC869 reported here is about 10 -fold higher than that reported previously (11), presumably because in the present case the mice were not starved prior to infection.

Clearance from the lungs, small intestine, cecum, large intestine, liver, spleen, and mesenteric lymph nodes. A nonlethal dose of AC869 and AC869-11 (10 7 CFU) was administered intranasally to CD-1 mice, and the mice were monitored for 14 days following treatment. Lungs, small intestine, cecum, large intestine, liver, spleen, and mesenteric lymph nodes were examined. At $3 \mathrm{~h}$ postadministration, $10^{7} \mathrm{CFU}$ of AC869 was found per $\mathrm{g}$ of lung tissue, whereas only $10^{5} \mathrm{CFU}$ per $\mathrm{g}$ of lung tissue of AC869-11 was found in the lungs at the same time 
(not shown). Thereafter, the two strains appeared to be cleared at the same rate; however, AC869-11 was completely cleared from the lungs by day 5 postadministration, whereas some of AC869 (about 10 CFU per $g$ of lung tissue) still remained (not shown). AC869 persisted in the small intestine, cecum, and large intestine for 10 to 14 days at about $10^{2} \mathrm{CFU}$ per $\mathrm{g}$ of tissue, and AC869 was found in the spleen, liver, and mesenteric lymph nodes at $3 \mathrm{~h}$ postadministration in fairly high numbers (about $10^{3} \mathrm{CFU}$ per $\mathrm{g}$ of tissue for each tissue), but not thereafter (not shown). In contrast, AC869-11 was observed only at $3 \mathrm{~h}$ postadministration in the small intestine, cecum, and large intestine but at levels 1,000-fold below that of AC869 (i.e., $10^{1}$ CFU per g of tissue for AC869-11 versus $10^{4}$ CFU per $\mathrm{g}$ of tissue for AC869) and was not found in spleen, liver, and mesenteric lymph nodes throughout the duration of the experiment (not shown).

Pulmonary inflammatory response. One day following intranasal treatment with $10^{7} \mathrm{CFU}$ of either AC869 or AC869-11 and at intervals thereafter for 14 days, cells were collected from the lungs by bronchoalveolar lavage. Although both AC869 and AC869-11 caused inflammation in the lungs for 2 days as judged by neutrophil infiltration, the inflammatory response induced by AC869-11 $\left(8.0 \times 10^{5}\right.$ neutrophils per ml of lung lavage fluid) was about fourfold less than that induced by $\mathrm{AC} 869\left(3.4 \times 10^{6}\right.$ neutrophils per $\mathrm{ml}$ of lung lavage fluid $)$ on day 2 postinfection. Neutrophils were not found in the lung lavage fluid of PBS-treated control mice.

Growth of AC869 and AC869-11 in LM, CM, and LB. The observed attenuation of AC869-11 relative to AC869 might be explained if AC869-11 grew more slowly in lung mucus than did AC869. However, the kinetics of growth (doubling times of about $44 \mathrm{~min}$ ) and the final yields of AC869 and AC869-11 (about $10^{9} \mathrm{CFU}$ per $\mathrm{ml}$ ) were identical. Growth rates and growth yields of the two strains in CM and LB were essentially identical to growth rates and growth yields in LM.

Immunoblot of $P$. aeruginosa AC869 and AC869-11 whole cells probed with CM-anti-AC869 serum. When LB-, CM-, and LM-grown cells were examined by immunoblotting with CManti-AC869 serum as the probe, the stepladder configuration which was observed in CM- and LM-grown AC869 was still observable in CM- and LM-grown AC869-11 but was far less intense than that observed with AC869 (not shown), suggesting that AC869-11 makes some O side chain when grown in CM and LM, but far less than does AC869.

Immunoblot of LPS isolated from AC869-11 probed with CM-anti-AC869 serum. LPS isolated from AC869-11 grown in LB, CM, and LM was probed with CM-anti-AC869 serum. Stepladder configurations were not observed, although faint traces of high-molecular-weight clusters were visible (Fig. 3, lanes 5, 6, and 7). However, the high-molecular-weight clusters were not visible when LPSs isolated from AC869-11 grown in LB, CM, and LM were silver stained (Fig. 2, lanes 5, 6, and 7). These data also suggest that AC869-11 is a mutant which contains some $\mathrm{O}$ side chain in $\mathrm{CM}$ and LM, but far less than strain AC869 under the same conditions.

Antibiotic sensitivity. AC869 and AC869-11 were grown in LM and LB containing different concentrations of antibiotics as described in Materials and Methods. MICs and MBCs were determined for the following antibiotics: $\beta$-lactams (ampicillin and carbenicillin), aminoglycosides (gentamicin, kanamycin, neomycin, and streptomycin), quinolones (nalidixic acid), tetracycline, and chloramphenicol. In both LM (Table 1) and LB (not shown), AC869-11 was more sensitive to ampicillin, gentamicin, kanamicin, neomycin, streptomycin, and tetracycline than was AC869 (Table 1). AC869-11 was more resistant to nalidixic acid than was AC869. There was no difference in the
TABLE 1. MICs and MBCs of $P$. aeruginosa AC869 and $\mathrm{AC} 869-11$ in $\mathrm{LM}^{a}$

\begin{tabular}{lccccc}
\hline \multirow{2}{*}{ Antibiotic } & \multicolumn{3}{c}{ Value for P. aeruginosa strain: } \\
\cline { 2 - 3 } \cline { 5 - 6 } \cline { 5 - 6 } & \multicolumn{2}{c}{ AC869 } & & \multicolumn{2}{c}{ AC869-11 } \\
\cline { 2 - 3 } \cline { 5 - 6 } & MIC & MBC & & MIC & MBC \\
\hline Ampicillin & 4,000 & 4,000 & & 250 & 1,000 \\
Carbenicillin & 31.25 & 31.25 & & 31.25 & 62.50 \\
Chloramphenicol & 200 & 400 & & 200 & 400 \\
Gentamicin & 6.25 & 12.50 & 6.25 & 6.25 \\
Kanamycin & 250 & 250 & & 62.5 & 125 \\
Nalidixic acid & 50 & 200 & & 50 & 400 \\
Neomycin & 50 & 50 & & 6.25 & 6.25 \\
Streptomycin & 25 & 25 & & 6.25 & 6.25 \\
Tetracycline & 25 & 50 & & 6.25 & 12.5 \\
\hline
\end{tabular}

${ }^{a}$ MICs and MBCs are expressed in micrograms per milliliter.

resistance of the two strains to chloramphenicol and carbenicillin (Table 1).

Extracellular protease activity. AC869 and AC869-11 were grown standing in $\mathrm{LB}$ for $24 \mathrm{~h}$ at $37^{\circ} \mathrm{C}$. Ten microliters of the cell-free supernatants of the AC869 and AC869-11 LB-grown cultures and twofold serial dilutions of the cell-free supernatants were pipetted onto casein agar plates. Extracellular protease activity (a clear zone on casein agar plates) was observable at dilutions of the AC869 supernatant as high as 16-fold, but not at 32 -fold. There was no protease activity in either the undiluted or the diluted LB AC869-11 supernatants. Therefore, AC869 grown in LB contained at least 16 times as much extracellular protease activity as did AC869-11 grown in LB. That AC869-11 makes some protease was shown by toothpicking from colonies on L agar to casein agar plates. After incubation for $24 \mathrm{~h}$ at $37^{\circ} \mathrm{C}$; small zones of casein hydrolysis surrounding the colonies were observed.

Exoenzyme S activity. Exoenzyme S, a $P$. aeruginosa ADPribosyltransferase, has been implicated in tissue damage (24). To determine whether exoenzyme $S$ production was altered in AC869-11, it and AC869 were grown under inducing (with NTA) and noninducing (without NTA) conditions for exoenzyme S synthesis and ADP-ribosyltransferase assays were performed with extracellular samples. In the presence of NTA, AC869-11 demonstrated about a twofold reduction in extracellular exoenzyme $\mathrm{S}$ activity relative to AC869 (22.19 \pm 1.73 $\mathrm{U}$ versus $40.19 \pm 17.7 \mathrm{U}$, respectively). In the absence of NTA, essentially no exoenzyme $S$ activity was observed $(0.06 \pm 0.06$ $\mathrm{U}$ for AC869 and $0.06 \pm 0.02 \mathrm{U}$ for AC869-11). These results suggested that AC869-11 has a defect in the ability to either synthesize or secrete active exoenzyme S.

To determine if the reduction in exoenzyme $\mathrm{S}$ activity correlated with a reduction in the amount of exoenzyme $S$ protein produced by AC869-11, immunoblot analysis was performed with antigens prepared from AC869 and AC869-11 (Fig. 5) and antisera specific for exoenzyme $S$ (9). The pattern of exoenzyme $\mathrm{S}$ antigen production correlated with the enzyme activity analysis, as the amount of immunoreactive products appeared to be reduced in each fraction of AC869-11 compared to AC869 (Fig. 5). Exoenzyme S was secreted in both strains. Moreover, the proportion of immunoreactive material that was cell associated (Fig. 5, lanes 2 and 6) and extracellular (Fig. 5, lanes 3 and 7) appeared to be approximately equal in AC869 and AC869-11. These data indicate that the mutation in AC869-11 did not alter exoenzyme S secretion but appeared to be related to the synthesis of exoenzyme $\mathrm{S}$. 


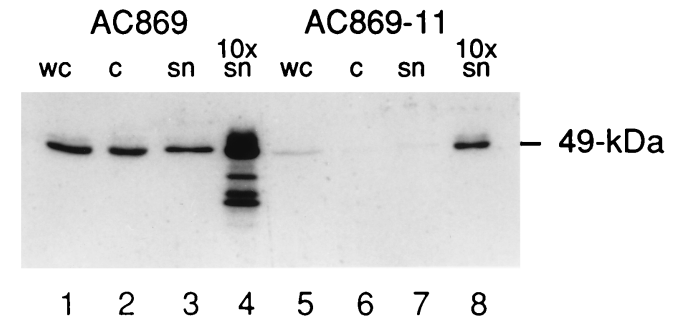

FIG. 5. Immunoblot analysis of cellular fractions of AC869 and AC869-11 for exoenzyme $\mathrm{S}$ antigen production. Samples were prepared as described in Materials and Methods from cultures grown under inducing conditions for exoenzyme S production. wc, whole culture; c, cellular lysate; sn, spent medium or culture supernatant; $10 \times \mathrm{sn}$, spent medium concentrated 10 -fold by ammonium sulfate precipitation. The migration of the $49-\mathrm{kDa}$ form of exoenzyme $\mathrm{S}$ is labeled.

Degradation of 3,5-dichlorobenzoate. To determine whether the mutation in AC869-11 altered its ability to degrade 3,5dichlorobenzoate, strains were inoculated $\left(10^{7} \mathrm{CFU} /\right.$ plate $)$ on M9 minimal medium agar plates containing 3,5-dichlorobenzoate $(1 \mathrm{mg} / \mathrm{ml})$ as sole carbon and energy source and were incubated at $30^{\circ} \mathrm{C}$ (see Materials and Methods). AC869-11 grew at the same rate as AC869 on M9 agar plates containing 3,5-dichlorobenzoate (8-h average doubling time) and to the same extent $\left(5 \times 10^{9} \mathrm{CFU} /\right.$ plate at $\left.72 \mathrm{~h}\right)$ but did not grow on M9 agar plates in the absence of a carbon source. Moreover, when AC869 and AC869-11 were spotted onto M9 agar medium containing 3,5-dichlorobenzoate as a carbon source and bromthymol blue as an acid-base indicator, both turned yellow after 2 days of incubation at $30^{\circ} \mathrm{C}$, indicating acid production during growth. These data indicate that strains AC869-11 and AC869 utilize 3,5-dichlorobenzoate as the sole carbon and energy source equally well. As a control, $P$. aeruginosa PAO1 was tested for its ability to utilize 3,5-dichlorobenzoate for growth. PAO1 grew on M9 agar plates containing glucose (1 $\mathrm{mg} / \mathrm{ml}$ ) as the sole carbon source but not on M9 plates containing 3,5-dichlorobenzoate.

Survival in 3,5-dichlorobenzoate-contaminated soil. AC869 and AC869-11 were inoculated into 3,5-dichlorobenzoate-contaminated soil $(0.25 \mathrm{mg} / \mathrm{g})$ at a level of $1.0 \times 10^{7} \mathrm{CFU} / \mathrm{g}$ (see Materials and Methods). Both strains survived equally well for approximately 1 week; however, thereafter AC869 persisted in soil at levels ranging between $10^{4}$ and $10^{6} \mathrm{CFU} / \mathrm{g}$, as observed previously for $P$. aeruginosa (30), whereas the level of AC86911 decreased continually until it was virtually undetectable (Fig. 6).

\section{DISCUSSION}

The goal of this study was to attenuate P. aeruginosa AC869 in mice without hampering its ability either to degrade 3,5dichlorobenzoate or to survive in the environment. Our approach was to grow AC869 in mouse lung mucus, mouse cecal mucus, and LB and determine whether mutants unable to make antigens expressed exclusively in lung and cecal mucus would lead to attenuation of AC869. We found that AC869 made far more $\mathrm{O}$ side chain on its LPS when grown in both lung and cecal mucus than when grown in LB and were able to isolate mutants that made little, if any, $O$ side chain under these conditions. Five of six mutants tested appeared to be as virulent as AC869 when administered to mice intranasally, suggesting that lack of $\mathrm{O}$ side chain was not sufficient for attenuation in the lungs of CD-1 mice. However, the sixth mutant tested, AC869-11, had an $\mathrm{LD}_{50}$ that was ninefold higher than that of AC869 (Fig. 4) but grew as well as AC869 with 3,5dichlorobenzoate as the sole carbon and energy source.

AC869-11 not only has less O side chain than AC869 on its surface but is defective in either synthesis or transport of extracellular proteases, which have been implicated in tissue destruction (1). Moreover, AC869-11 is far more sensitive to a number of antibiotics than is AC869 (Table 1). Changes in susceptibility to antibiotics in undefined $P$. aeruginosa LPS mutants have been noted previously $(17,18)$. If the defect in AC869-11 is in transport, it could be in a gene encoding a protein common to and necessary for the export of LPS, extracellular protease, and antibiotics through the membrane. In this case, the mutation in $P$. aeruginosa AC869-11 would cause several export systems to be less functional and would result in diminished secretion of virulence factors and decreased efflux of antibiotics, without affecting their influx. $P$. aeruginosa is known to have at least one efflux system for antibiotics, which contributes to its naturally high resistance (25). At the present time, however, we favor the hypothesis that $P$. aeruginosa AC869-11 is defective in regulation of expression of several virulence genes, since it made far less exoenzyme $S$ than AC869 but appeared to secrete it normally (Fig. 5).

AC869-11 degraded 3,5-dichlorobenzoate as well as AC869 under controlled laboratory conditions. However, AC869-11 did not survive in 3,5-dichlorobenzoate-contaminated sterile soil as well as AC869 after 1 week (Fig. 6). Therefore, in the present case, it appears that the mutation which resulted in attenuation of $P$. aeruginosa AC869-11 in the lungs of CD-1 mice also resulted in attenuation of its ability to survive in soil. To our knowledge (by use of the Medline Express [1966 to 1996] database), the present study is the only one in which an attempt has been made to isolate a $P$. aeruginosa mutant that is attenuated when administered intranasally to mice and to determine whether it remains strong in the environment. Whether it is a general rule that mutations resulting in pulmonary attenuation of $P$. aeruginosa also result in weakness in the environment remains to be seen. It should be noted, however, that despite weakness in the environment, strains like AC86911 may prove to be useful in bioreactors, under controlled conditions, in which they remain fully capable of degrading

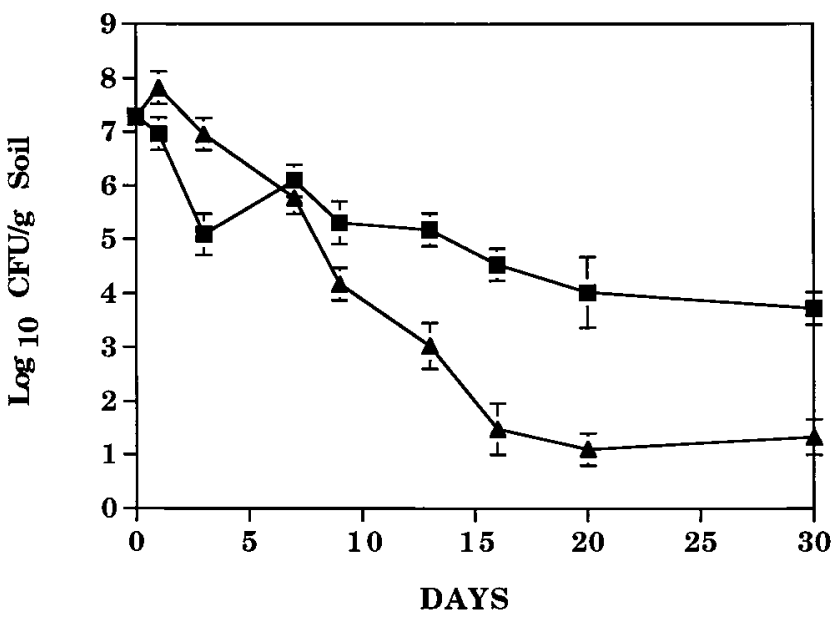

FIG. 6. Survival of AC869 and AC869-11 in 3,5-dichlorobenzoate-contaminated soil. Soil samples contaminated with 3,5-dichlorobenzoate were inoculated with either AC869 (ם) or AC869-11 ( $\mathbf{\Delta})$ and sampled at the indicated times as described in Materials and Methods. Error bars represent the standard errors of the $\log _{10}$ mean CFU per gram of soil. 
toxic compounds without posing a serious threat to human health.

\section{ACKNOWLEDGMENTS}

We thank A. M. B. Kropinski of the University of Guelph for bacteriophage E79. We gratefully acknowledge the excellent technical assistance of D. Mac Richardson. We also thank Paul Johnson for his photographic skills

This investigation was supported by U.S. Environmental Protection Agency Assistance Agreement CR 820422-02-0 to P. S. Cohen.

\section{REFERENCES}

1. Blackwood, L. L., R. M. Stone, B. H. Iglewski, and J. E. Pennington. 1983. Evaluation of Pseudomonas aeruginosa exotoxin A and elastase as virulence factors in acute lung infection. Infect. Immun. 39:198-201.

2. Bodey, G. P., R. Bolivar, V. Fainstein, and L. Jadeja. 1983. Infections caused by Pseudomonas aeruginosa. Rev. Infect. Dis. 5:279-313.

3. Bodey, G. P., V. Rodriguez, H.-Y. Chang, and G. Narboni. 1978. Fever and infection in leukemic patients. Cancer 41:1610-1622.

4. Bradford, M. M. 1976. A rapid and sensitive method for the quantitation of microgram quantities of protein utilizing the principle of protein-dye binding. Anal. Biochem. 72:248-254.

5. Chatterjee, D. K., and A. M. Chakrabarty. 1982. Genetic rearrangements in plasmids specifying degradation of chlorinated benzoic acids. Mol. Gen. Genet. 188:279-285.

6. Coburn, J. 1992. Pseudomonas aeruginosa exoenzyme S. Curr. Top. Microbiol. Immunol. 175:133-143.

7. Cohen, P. S., J. C. Arruda, T. J. Williams, and D. C. Laux. 1985. Adhesion of a human fecal Escherichia coli strain to mouse colonic mucus. Infect. Immun. 48:139-145.

8. Dubray, G., and G. Bezard. 1982. A highly sensitive periodic acid-silver stain for 1,2-diol groups of glycoproteins and polysaccharides in polyacrylamide gels. Anal. Biochem. 119:325-329.

9. Frank, D. W., and B. H. Iglewski. 1991. Cloning and sequence analysis of a trans-regulatory locus required for exoenzyme S synthesis in Pseudomonas aeruginosa. J. Bacteriol. 173:6460-6468.

10. Frank, D. W., G. Nair, and H. P. Schweizer. 1994. Construction and characterization of chromosomal insertional mutations of the Pseudomonas aeruginosa exoenzyme S trans-regulatory locus. Infect. Immun. 62:554-563.

11. George, S. E., M. J. Kohan, M. I. Gilmour, M. S. Taylor, H. G. Brooks, J. P. Creason, and L. D. Claxton. 1993. Pulmonary clearance and inflammatory response in $\mathrm{C} 3 \mathrm{H} / \mathrm{HeJ}$ mice after intranasal exposure to Pseudomonas spp. Appl. Environ. Microbiol. 59:3585-3591.

12. Guiot, H. F. L., J. W. M. van der Meer, and R. van Furth. 1981. Selective antimicrobial modulation of human microbial flora: infection prevention in patients with decreased host defense mechanisms by selective elimination of potentially pathogenic bacteria. J. Infect. Dis. 143:644-654.

13. Holloway, B. W., V. Krishnapillae, and A. F. Morgan. 1979. Chromosomal genetics of Pseudomonas. Microbiol. Rev. 43:73-102.

14. Jarrell, K., and A. M. Kropinski. 1977. Identification of the cell wall receptor for bacteriophage E79 in Pseudomonas aeruginosa strain PAO. J. Virol. 23:461-466.

15. Karkhanis, Y. D., J. Y. Zeltner, J. J. Jackson, and D. J. Carlo. 1978. A new and improved microassay to determine 2-keto-3-deoxyoctonate in lipopolysaccharide of gram-negative bacteria. Anal. Biochem. 85:595-601.

16. Kropinski, A. M., L. C. Chan, and F. H. Milazzo. 1979. The extraction and analysis of lipopolysaccharides from Pseudomonas aeruginosa strain PAO1, and three rough mutants. Can. J. Microbiol. 25:390-398.

17. Kropinski, A. M., J. Kuzio, B. L. Angus, and R. E. W. Hancock. 1982. Chemical and chromatographic analysis of lipopolysaccharide from an antibiotic-supersusceptible mutant of Pseudomonas aeruginosa. Antimicrob. Agents Chemother. 21:310-319.

18. Kropinski, A. M. B., L. Chan, and F. H. Milazzo. 1978. Susceptibility of lipopolysaccharide-defective mutants of Pseudomonas aeruginosa strain PAO to dyes, detergents, and antibiotics. Antimicrob. Agents Chemother. 13:494499.

19. Leahy, J. G., and R. R. Colwell. 1990. Microbial degradation of hydrocarbons in the environment. Microbiol. Rev. 54:305-315.

20. Lindow, S. E. 1985. Ecology of Pseudomonas syringae relevant to field use of Ice $^{-}$deletion mutants constructed in vitro for plant frost control, p. 23-25. In H. O. Halvorson, D. Pramer, and M. Rogul (ed.), Engineered organisms in the environment: scientific issues. American Society for Microbiology, Washington, D.C.

21. Liu, P. V., H. Matsumoto, H. Kusama, and T. Bergan. 1983. Survey of heat-stable, major somatic antigens of Pseudomonas aeruginosa. Int. J. Syst. Bacteriol. 33:256-264.

22. McGroarty, E. J., and M. Rivera. 1990. Growth-dependent alterations in production of serotype-specific and common antigen lipopolysaccharides in Pseudomonas aeruginosa PAO1. Infect. Immun. 58:1030-1037.

23. Miller, J. H. 1972. Experiments in molecular genetics. Cold Spring Harbor Laboratory, Cold Spring Harbor, N.Y.

24. Nicas, T. I., J. Bradley, J. E. Lochner, and B. H. Iglewski. 1985. The role of exoenzyme S in infections with Pseudomonas aeruginosa. J. Infect. Dis. 152: 716-721.

25. Nikaido, H. 1994. Prevention of drug access to bacterial targets: permeability barriers and active efflux. Science 264:382-387.

26. Obukowicz, M. G., F. J. Perlak, K. Kusano-Kretzmer, E. J. Mayer, S. L. Bolten, and L. S. Watrud. 1986. Tn5-mediated integration of the deltaendotoxin gene from Bacillus thuringiensis into chromosome of the rootcolonizing pseudomonads. J. Bacteriol. 168:982-989.

26a.Orskov, I., and F. Orskov. Personal communication.

27. Schimpff, S. C. 1980. Infection prevention during profound granulocytopenia. New approaches to alimentary canal microbial suppression. Ann. Intern. Med. 93:358-361.

28. Thompson, M. R., M. J. Bjorn, P. A. Sokol, J. D. Lile, and B. H. Iglewski. 1980. Exoenzyme S: an ADP-ribosyl transferase produced by Pseudomonas aeruginosa, p. 425-433. In M. Smulson and T. Sugimura (ed.), Novel ADPribosylation of regulatory enzymes and proteins. Elsevier/North-Holland Inc., Amsterdam, The Netherlands.

29. Vogel, H. J., and D. M. Bonner. 1956. Acetylornithinase of Escherichia coli: partial purification and some properties. J. Biol. Chem. 218:97-106.

30. Zechman, J. M., and L. E. Casida, Jr. 1982. Death of Pseudomonas aeruginosa in soil. Can. J. Microbiol. 28:788-794. 